Organo- and

Phosphoric Acid Diesters as Efficient Catalysts for Hydroaminations of Nonactivated Alkenes and an Application to Asymmetric Hydroaminations

Synlett 2008, 995-998.

Biocatalysis

\title{
Hydroamination of Nonactivated Alkenes
}

Key words

hydroamination

phosphoric acid

alkenes

cycloisomerization

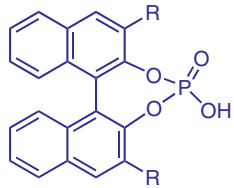

1: $\mathrm{R}=\mathrm{SiPh}_{3}$

(R)-1a: $\mathrm{R}=3,5-\left(\mathrm{F}_{3} \mathrm{C}\right)_{2} \mathrm{C}_{6} \mathrm{H}_{3}$

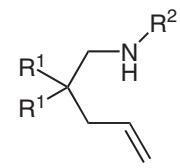

1 (10-20 mol\%)

or

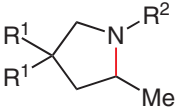

(R)-1a (20 mol\%)

1,4-dioxane, $130^{\circ} \mathrm{C}, 20 \mathrm{~h}$

Selected examples:<smiles>O=[N+]([O-])C1CC(c2ccccc2)CN1O</smiles>

$93 \%$ yield<smiles>CN1CC(c2ccccc2)CC1[N+](=O)[O-]</smiles>

$85 \%$ yield

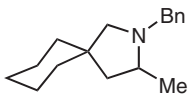

$53 \%$ yield<smiles>O=[N+](c1ccccc1)C1CC(c2ccccc2)CN1Cc1ccc(Br)cc1</smiles>

$\mathrm{R}=\mathrm{OMe}, \mathrm{NO}_{2}, \mathrm{CO}_{2} \mathrm{Me}$ or $\mathrm{Cl}$ 95-97\% yield

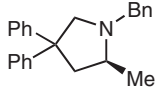

$72 \%$ yield er $=58.5: 41.5$
Significance: A catalytic amount of Brønsted acid enables high yielding intramolecular hydroaminations of electronically unactivated alkenes with basic amines. Screenings identified phosphoric acid $\mathbf{1}$ as the most active catalyst for this cycloisomerization. Substrates with ether, nitro, ester, or chloro functionalities are tolerated. By using enantiomerically pure phosphoric acid $(R)-\mathbf{1 a}$ the authors show an unprecedented example of a metal-free asymmetric hydroamination of nonactivated alkenes, albeit with modest selectivity (er = 58.5:41.5).
Comment: This intramolecular addition of an amine to a $\mathrm{C}-\mathrm{C}$ double bond depicts a direct and atom-economical access to $\mathrm{N}$-heterocycles, which are ubiquitous in natural products as well as biologically active compounds. Most organocatalytic additions of $\mathrm{N}$-nucleophiles to olefins require activation of the alkene functionality. The observed effectiveness of this addition might be due to the intramolecular nature of this cycloisomerization. A screening of different enantiopure phosphoric acids might result in higher enantiomeric ratios. 